\title{
Flurry of deal-making surrounds new autoimmunity target
}

In autoimmune diseases ranging from psoriasis to Crohn's disease, an excess of T helper 17 $\left(\mathrm{T}_{\mathrm{H}} 17\right)$ cells, and the cytokine signaling molecules they produce, is a dominant factor in keeping the immune system in constant overdrive. Clinical approaches to targeting this firehose of immune activation have largely taken one approach: blocking overabundant cytokines. But recent research on a previously underappreciated receptor suggests that there could be a better approach. By modulating the activity of a protein called retinoic acidrelated orphan receptor-gamma $\mathrm{t}(\mathrm{ROR} \gamma \mathrm{t})$, scientists have discovered they can prevent the differentiation of $\mathrm{T}_{\mathrm{H}} 17$ cells from $\mathrm{T}$ cell precursors in the thymus.

The findings have led to a flurry of activity among large drug companies seeking to add ROR $\gamma$ t research programs to their portfolios. Most recently, on 31 July, Amgen, the California biotech giant, announced a collaboration with Japan-based Teijin Pharma Limited to discover, develop and commercialize small-molecule drugs that target ROR $\gamma \mathrm{t}$.

The beauty of this strategy, says immunologist Dan Littman, whose lab at the New York University Langone Medical Center has been responsible for many of the key findings related to this receptor, is that because ROR $\gamma$ t modulators act directly on $\mathrm{T}_{\mathrm{H}} 17$ cell development, they would affect all downstream cytokine pathways. In contrast, attempts to block particular cytokines produced by $\mathrm{T}_{\mathrm{H}} 17$ cells, such as interleukin-17 (IL-17), still leave production of other cytokines intact. "The cytokine antibodies in development really only hit a part of this pathway, whereas targeting ROR $\gamma t$ lets us hit all of it," Littman says.

The ROR $\gamma$ t protein is part of a larger family of receptors within the nucleus that bind response elements in the genome to influence the expression of a multitude of genes. Researchers have known since the 1990s that ROR $\gamma t$ is important for T cell differentiation, but it wasn't until more recently, after $\mathrm{T}_{\mathrm{H}} 17$ cells were discovered in 2007 , that the link to autoimmune disease became apparent. Researchers quickly unraveled the specific effect of this receptor on $\mathrm{T}_{\mathrm{H}} 17$ cell development, and, in 2011, a group from the Scripps Research Institute in Jupiter, Florida, showed for the first time that a synthetic ligand that bound ROR $\gamma \mathrm{t}$ inhibited both the differentiation and function of $\mathrm{T}_{\mathrm{H}} 17$ cells and lessened the symptoms of a mouse model of multiple sclerosis (Nature 472, 491-494, 2011).

The effects of blocking ROR $\gamma \mathrm{t}$ on the immune system, particularly the decrease

Hear the ROR $\gamma$ t: Drug companies with programs and partnerships aimed at ROR $\gamma$ t modulators.

\begin{tabular}{lll} 
Company & Partner & Year partnership established \\
Orphagen & Japan Tobacco & 2009 \\
\hline Tempero & GlaxoSmithKline & 2009 \\
Exelixis & Bristol-Myers Squibb & 2010 \\
Lycera & Merck & 2011 \\
Karo Bio & Pfizer & 2011 \\
\hline Phenex & Janssen Biotech & 2012 \\
Teijin & Amgen & 2013 \\
Vitae & To be announced & Deal expected by October
\end{tabular}

in $\mathrm{T}_{\mathrm{H}} 17$ cells, were immediately clear. But what degree of inhibition is required, and whether such blocking drugs have off-target effects in organs such as the liver, still needs investigation. "The big question remaining is what ROR $\gamma \mathrm{t}$, or the lack of it, does in other tissues," says biochemist Patrick Griffin, who was part of the Scripps team that developed and studied the ligands. Unpublished results out of his lab suggest that complete inhibition of ROR $\gamma t$ can lead to opportunistic infections. So, doses of drug that allow low levels of continued ROR $\gamma$ t activation may provide the best balance of efficacy and safety, he says.

Jianfei Yang, a principal scientist at Tempero Pharmaceuticals, agrees that more work is needed to understand the broader systematic effects of ROR $\gamma$ t inhibitors. At Tempero, a Cambridge, Massachusetts-based subsidiary of GlaxoSmithKline, Yang and his colleagues have focused on identifying compounds that bind ROR $\gamma$ t but not other highly similar RORs such as ROR $\alpha$, as the Scripps compound does. He's already found a few drugs that fit the bill. Last October, at the International Conference on Clinical \& Cellular Immunology in Chicago, Yang presented results on several compounds that block ROR $\gamma$ t activity, and his team has developed additional compounds since.

\section{Off to a rip-RORing start}

Tempero isn't the only company on the hunt for such drugs. Since 2010, many big pharma firms, including Bristol-Myers Squibb, Merck and Pfizer, have partnered with smaller companies pursuing ROR $\gamma \mathrm{t}$ inhibitors (see 'Hear the ROR $\gamma \mathrm{t}$ '). The companies all remain tight-lipped about when their programs could move from preclinical work to clinical studies. But, as Yang points out, "whoever goes to clinical trials first will not necessarily win this race. What will matter is who gets the best compound."

If the ligands live up to their promise in selectively decreasing the prevalence of
$\mathrm{T}_{\mathrm{H}} 17$ cells without side effects, they could be poised to make a large market impact, says Ling Zhuang, a life sciences analyst at the London office of the research firm GlobalData. The drugs would have to outperform existing blockbuster antibody drugs including Humira (adalimumab) and Remicade (infliximab), both of which target the inflammatory cytokine tumor necrosis factor alpha, as well as IL-17 blockers now in late-stage clinical development (see Nat. Med. 18, 638, 2012). But all those drugs are only available as injectables, and an oral ROR $\gamma t$ pill — even one that doesn't outperform in efficacy, as many researchers are hoping - would have a leg up on delivery method preference among patients and doctors.

"Should ROR modulators prove to be effective, safe and with few side effects, they are likely to be used as first-line treatments," Zhuang says.

The earliest applications of the ROR $\gamma \mathrm{t}$ modulators will likely be in diseases which have already been validated to be linked to $T_{H} 17$ cells and IL-17 signaling through cytokine antibody studies, he adds. Such conditions include multiple sclerosis, psoriasis, asthma, rheumatoid arthritis, inflammatory bowel disease and systemic lupus erythematosus.

Sarah C P Williams

\section{Corrections}

In the August 2013 Biomedical Briefing (Nat. Med. 19, 956-957, 2013), the chart showing worldwide total pharmaceutical R\&D spending 2004-2018 failed to indicate that the values for 2013-2018 are projected numbers. The error has been corrected in the HTML and PDF versions of the article.

In the August 2013 news feature "A future, on ice" (Nat. Med. 19, 958-961, 2013), Kutluk Oktay's last name was misspelled as Otkay in one instance. The error has been corrected in the HTML and PDF versions of the article. 